\title{
Editorial
}

\section{What do we mean when we use the word bealth?}

\author{
Phyllis Freeman \\ Co-Editor \\ E-mail: jphp@umb.edu
}

Journal of Public Health Policy (2014) 35, 357-362. doi:Io.IO57/jphp.20I4.28; published online I9 June 2014

The founding editor of the Journal of Public Health Policy (JPHP), Milton Terris, posted the phrase Theory is the eye of practice on the journal's masthead. In that spirit, we introduce a Special Section discussing the meaning of the word, or concept, health. We are all in favor of better health, but what do we mean by good or poor health? Could we agree? What is the importance of updating discussion of these meanings and forging greater agreement - both for public health efforts to prevent avoidable illness, disability, and death and for the care of individuals already afflicted?

JPHP occupies a special niche in the world of scholarly journals - to draw attention to improving population health, particularly protecting the population from avoidable sources of illness or injury. Whether the problems are old and intractable, or especially menacing because they are novel and little understood, JPHP's primary mission is to publish original articles and commentaries about opportunities to improve health at the population level. As so many publications dedicate themselves to medical sciences and services, we usually leave the domain of personal services for patients to the medical publications.

Even when intending to address population health challenges, we are all too aware of an insidious habit of thought, even among public health practitioners and academics, to use medical terminology. As editors we frequently read submissions where authors use the words 'health reform' when addressing only systems of finance for medical services - never mentioning, for example, protecting populations from dangerous exposures. Furthermore, in many countries, public health may refer principally to government-supported medical services rather than to 
population health analysis and intervention. These confusions and differences in use largely reinforce the primacy of individual level thinking about health, that is, for patients in medical care - rather than for preventing damaging exposures. Once people are patients, it is likely they found themselves in harm's way where they lived, worked, studied, or recreated - possibly years before experiencing symptoms for which they may seek care.

The infrastructure for population health worldwide is thus enfeebled and undervalued.

Aside from moments of obvious crisis, lack of appreciation for opportunities to ferret out and correct problems at their sources dissipates a collective sense of urgency. This urgency is desperately needed to drive protection of people from avoidable harm. In the public health community we know so well how to prevent a multitude of health problems, but we appear to know far less about how to gather sufficient political will to do so.

How does this relate to this Special Section? We ask readers to bear in mind that many effective responses to preventable health problems do not require debate in scholarly journals. Debates, even among the wellintentioned, can often reduce our sense of urgency to act on what we know already. Public health, at its best, is impatient. We hope to encourage a debate that takes into account what can and should be done now - even as we consider the questions raised and addressed by Bircher and Kuruvilla and those who have commented as part of a quest for wisdom that will make future action more effective.

Now we introduce the genesis, players, and papers in the Special Section.

\section{Genesis of this Special Section}

The original, unsolicited submission by Johannes Bircher - that has become the lead piece by Bircher and Kuruvilla - intrigued me, even though its realm of reference was largely the health of individuals. Surely any probing of the meaning of health must have important implications as well for population - or as we use the term - public health.

We sent the Bircher manuscript to review, including to a member of our Editorial Board, Shyama Kuruvilla, as she has a philosophical bent and works on population strategies in maternal and child health. She cautioned us about the suitability of the article for JPHP given its focus on individual health. At the same time, her comprehensive review of

358 () 2014 Macmillan Publishers Ltd. or 97-5897 Journal of Public Health Policy Vol. 35, 3, 357-362 
other aspects of the text provoked the original author to ask for more information about this reviewer. We sought her permission and introduced the two of them. Thus began not just a discussion, but an intensive collaboration, ultimately as coauthors.

As we worked with the authors through many drafts, we acceded to something very rare for JPHP - a double length paper - as they present a theory, discuss its early application, and expand it to include a population perspective.

Even before meeting Kuruvilla, Bircher had used an earlier iteration of his model of health to assist a non-governmental organization (NGO) in India. Their work with government, other NGOs, health practitioners, and villagers in a very low-resource district (Odisha) aimed to improve health in more than Ioo small communities. As Kuruvilla is regularly in contact with governments shaping policies to address population challenges, she had at hand other examples of communities where health improvements have been supported by modes of analysis similar to the model Bircher had been developing.

As the population perspective has been recently added, this component is being subjected to probing and critique for the first time. Thus, we ask our readers to add your thoughts to this discussion. We hope this Special Section will provoke debate and we welcome Letters to the Editors at: JPHP@umb.edu.

\section{The topics and authors}

The Special Section begins with a quite elegant piece entitled Defining Health by Addressing Individual, Social, and Environmental Determinants: New Opportunities for Health Care and Public Health. ${ }^{\mathrm{I}}$ Its authors, Johannes Bircher and Shyama Kuruvilla, propose a new 'operational' way to understand and assess health. They do so to focus and enliven discussions - discussions they envision taking place among teams - be they interdisciplinary teams caring for patients in medical care settings, teams in villages working to improve sanitation, nutrition, and reduce environmental pollution, or teams of international organization members debating how health will figure in future strategies. These strategies aim to hasten development - with improving health as an objective across sectors as a central component. Development assistance will be directed across multiple sectors (agriculture, education, energy, environment, health, transportation, and so on) to encourage and assist 
middle and especially lower income countries organize more effective activities to improve health and development overall. At any moment, the locus of analysis and activity might be a small village in China or Mexico, a populous district in India or Uganda, a local health care center in Peru or Papua New Guinea, or a hospital in France or Egypt - any setting where people come together to improve the health of populations or individuals.

For the moment we put aside the inevitability of actors who may attach higher priority to other pursuits, wealth, for example, who will be absent from or undermining those who will team up to cooperate. The fight against tobacco and the role of that of industry is one obvious example.

We solicited the commentaries below (along with invitations to others who did not take us up), and we did not submit them to peer review. Many other perspectives could enrich the discussion but are not yet represented.

The first two comments tell of early experiences using the Model. Both authors are associates of Johannes Bircher, and at our request, he introduced us to them.

- Sarangadhar Samal uses the Model as a foundation for organizing (by the National Youth Service Action and Social Development Research Institute - an NGO he leads in India) in villages to redress known hazards (for example, sanitation, lack of nutritious food) and to encourage health promoting activities. ${ }^{2}$

- Jörg Jeger, a medical doctor, directs a Swiss institute responsible for assessing the health of applicants for social security benefits, including disability insurance. He uses the Model in his work and finds it particularly well suited to evaluating patients with chronic illness. He also sees applicability to certain public health challenges. ${ }^{3}$

Then three highly experienced public health colleagues take up the debate.

- Elena Naumova, JPHP's statistical editor, warns that the model does not adequately balance societal responsibilities against those of individuals, and lacks a future perspective. She raises an intriguing set of questions for consideration and makes specific suggestions. $^{4}$ 
- Julio Frenk and Octavio Gómez-Dántes argue in favor of moving away from a single definition about health as a state of being, and toward a framework for evaluating elements of health as a dynamic process. ${ }^{5}$ Both medical doctors are steeped in theory - and in practice - at the highest levels of responsibility.

- David Ozonoff, an environmental health specialist with a longstanding interest in public health history, challenges several assumptions intrinsic to choosing a health focus. ${ }^{6}$ He points out that populations may be healthy as populations, but not be a population of healthy individuals - and vice versa.

Next comes a perspective of health professions students eager for an education about health that will be more conducive to social action. When we hope that medical doctors will be in the vanguard to protect the health of populations, we are confronted by difficult circumstances. How many doctors have been inside a big dangerous foundry or poultry processing plant? Lived or worked in a crowded slum? Studied sewage or water treatment plants? Or watched crop dusters contaminate agricultural environments where people live and work? For medical students, largely from middle-class families, these environmental realities are too often airbrushed aside and replaced with medical terms and diagnoses attached to individuals.

- Joško Miše, President of the International Federation of Medical Students' Associations describes survey results indicating desire and need for more interdisciplinary education and wonders if a better definition of health could improve health professions education. ${ }^{7}$

The final two comments focus on elements of the Model from a medical perspective:

- Joachim Sturmberg from Monash University in Melbourne, Australia (one of the original reviewers of the Bircher paper) offers a constructive critique of an element of the theory of the Meikrich Model of Health - based on his long immersion in this subject matter. $^{8}$

- Peter J. Meier-Abt, President of the Swiss Academy of Medical Sciences, completes the commentaries. He explains how Bircher developed the Model as part of an academy project to shape the 


\title{
future of medicine. Then he concentrates on applicability of the Model to the area of 'personalized health' or 'personalized medicine'.'
}

\author{
We hope this Special Section will provoke deeper thought about the \\ meaning of health, and again, we invite your letters (at JPHP@umb.edu). \\ We especially look forward to perspectives for increasing urgency and \\ ever more effective action.
}

\section{References}

I. Bircher, J. and Kuruvilla, S. (20I4) Defining health by addressing individual, social, and environmental determinants: New opportunities for health care and public health. Journal of Public Health Policy doi:Io.I057/jphp.20I4.I9, published online I9 June 20I4.

2. Samal, S. (20I4) Implementation of the Meikirch Model in Odisha, India. Journal of Public Health Policy doi:IO.I057/jphp.20I4.22, published online I9 June 20 I 4.

3. Jeger, J. (20I4) Application of the Meikirch Model to independent medical evaluations for Social Security eligibility determinations in Switzerland and potential for use by physicians in many other situations. Journal of Public Health Policy doi:Io.I057/jphp.20I4.2I, published online I9 June 2014.

4. Naumove, E.N. (20I4) A cautionary note for population health: Disproportionate emphasis on personal responsibility for health and wellbeing. Journal of Public Health Policy doi:I0.1057/ jphp.20I4.23, published online I9 June 2014.

5. Frenk, J. and Gómez-Dantés, O. (20I4) Designing a framework for the concept of health. Journal of Public Health Policy doi:I0.1057/jphp.20I4.26, published online I9 June 2014.

6. Ozonoff, D. (20I4) Choosing health. Journal of Public Health Policy doi: I0.I057/jphp.20I4.24, published online I9 June 20I4.

7. Miše, J. (2OI4) Impatience of health professions students for health equity - Can a new definition help? Journal of Public Health Policy doi:I0.I057/jphp.20I4.25, published online I9 June 20 I 4.

8. Sturmberg, J.P. (2OI4) Emergent properties define the subjective nature of health and dis-ease. Journal of Public Health Policy doi:IO.I057/jphp.20I4.20, published online I9 June 20 I 4.

9. Meier-Abt, P.J. (2OI4) The Meikirch Model of Health fits well into the concept of 'personalized health'. Journal of Public Health Policy doi:I0.I057/jphp.20I4.27, published online I9 June 20 I 4. 